\title{
Background diet influences the anti-inflammatory effect of $\alpha$-linolenic acid in dyslipidaemic subjects
}

\author{
George K. Paschos ${ }^{1}$, Loukianos S. Rallidis ${ }^{2}$, Georgios K. Liakos ${ }^{3}$, Demosthenes Panagiotakos ${ }^{1}$, \\ George Anastasiadis ${ }^{4}$, Vasilios Votteas ${ }^{4}$ and Antonis Zampelas ${ }^{1 *}$ \\ ${ }^{1}$ Department of Nutrition and Dietetics, Harokopio University, 70 El Venizelou Street, Athens 17671, Greece \\ ${ }^{2}$ Second Department of Cardiology, General Hospital of Nikea, Piraeus, Greece \\ ${ }^{3}$ Biochemistry Laboratory, General Hospital of Nikea, Piraeus, Greece \\ ${ }^{4}$ Department of Cardiology, Laiko Hospital, Athens, Greece
}

(Received 15 December 2003 - Revised 18 May 2004 - Accepted 2 June 2004)

\begin{abstract}
Long-chain $n$-3 PUFA from fish oils are known to have anti-inflammatory effects. We evaluated the effect of $\alpha$-linolenic acid (ALA), precursor of $n-3$ fatty acids, on serum inflammatory markers and soluble cellular adhesion molecules (sCAM) of dyslipidaemic males, relative to their background diet. Participants were assigned to two groups, based upon food intake patterns: (a) twenty-one dyslipidaemic subjects who habitually ate a Mediterranean-Cretan-type diet; (b) nineteen dyslipidaemic subjects who normally ate a Westernised Greek diet. All were supplemented with $8.1 \mathrm{~g} \mathrm{ALA} / \mathrm{d}$ for 12 weeks. We determined serum amyloid A (SAA), C-reactive protein (CRP), macrophage colony-stimulating factor (MCSF), IL-6, soluble vascular cell adhesion molecule-1 (sVCAM-1), soluble intercellular adhesion molecule-1 and soluble E-selectin concentrations at the beginning and the end of the ALA supplementation period. Serum baseline concentrations of inflammatory markers and SCAM were similar across the diet groups. Type of diet had a significant impact on the response of inflammatory markers to ALA supplementation. The Westernised Greek diet group showed a reduction in SAA $(P<0.001)$, CRP $(P=0.002)$, MCSF $(P=0.005)$ and IL-6 $(P=0.04)$ concentrations. The Mediterranean-Cretan-type background diet group showed a significant reduction only in MCSF concentrations $(P=0 \cdot 003)$. The sVCAM-1 concentrations were significantly reduced in both the Westernised Greek diet group $(P=0.001)$ and the Mediterranean-Cretan-type diet group $(P<0 \cdot 001)$. The present study demonstrated that ALA supplementation lowered the serum concentrations of inflammatory markers more profoundly when the background diet was rich in saturated fatty acids and poor in MUFA.
\end{abstract}

$\alpha$-Linolenic acid: Mediterranean diet: Inflammatory markers: Cellular adhesion molecules

Consumption of diets rich in $n-3$ fatty acids has been linked with low prevalence of atherosclerosis (Ascherio et al. 1995). Furthermore, $n-3$ fatty acids have been used to treat various chronic inflammatory conditions and have been shown to have anti-inflammatory properties (Calder, 2001). Immune system cells are inherent parts of inflammatory events involved in the development and progression of atherosclerosis. The adhesion of circulating blood monocytes to the endothelial cells and their subsequent transmigration across the vascular endothelium are prerequisite steps in the pathogenesis of the disease (Ross, 1999). It has been proposed that the anti-inflammatory properties of $n-3$ fatty acids can explain the correlation with the low prevalence of atherosclerosis (Calder, 2001). However, other human studies do not confirm the antiinflammatory effect of $n-3$ PUFA.

Previous studies have shown variable results when reporting effects of $n-3$ PUFA on cytokine production by mononuclear cells. Dietary supplementation studies with EPA and docosahexaenoic acid (DHA) have shown a decrease in monocyte synthesis of TNF- $\alpha$, IL- $1 \beta$ and IL-6 in healthy subjects (Endres et al. 1989; Meydani et al. 1991; Caughey et al. 1996). In contrast, other studies documented a lack of effect of $n-3$ PUFA on the synthesis of the same cytokines (Schmidt et al. 1996; Blok et al. 1997; Yaqoob et al. 2000). The effects of $\alpha$-linolenic acid (ALA), the precursor of EPA and DHA, on inflammatory markers are also controversial. In particular, on the one hand, it has been reported that the production of TNF- $\alpha$ and IL-1 $\beta$ was suppressed by lipopolysaccharidestimulated monocytes of healthy volunteers after a high dose of dietary ALA (Caughey et al. 1996). In addition, in our previous report (Rallidis et al. 2003), supplementation with ALA reduced serum IL- 6 and C-reactive protein (CRP) concentrations. On the other hand, other research has demonstrated that ALA did not affect the

\footnotetext{
Abbreviations: ALA, $\alpha$-linolenic acid; CRP, C-reactive protein; DHA, docosahexaenoic acid; MCSF, macrophage colony-stimulating factor; SAA, serum amyloid A; sCAM, soluble cellular adhesion molecules.

* Corresponding author: Dr Antonis Zampelas, fax + 30210 9549141, email azampelas@hua.gr
} 
production of TNF- $\alpha$, IL-1 $\beta$, IL-6, IL- 2 or interferon- $\gamma$ by mononuclear cells (Thies et al. 2001). Recent evidence has documented that intake levels of $\leq 9.5 \mathrm{~g} \mathrm{ALA} / \mathrm{d}$ or $\leq 1.7 \mathrm{~g}$ $\mathrm{EPA}+\mathrm{DHA} / \mathrm{d}$ did not alter the production of cytokines by monocytes and lymphocytes although the fatty acid composition of mononuclear cells was significantly altered (Kew et al. 2003).

A number of in vitro studies suggest a suppressive effect of $n-3$ fatty acids on adhesion molecule expression by vascular endothelial cells (De Caterina et al. 1994; Weber et al. 1995; Khalfoun et al. 1996; Collie-Duguid \& Wahle, 1996). Results from human supplementation studies, however, are inconsistent. Some have shown that supplementation with EPA+DHA reduced the plasma concentration of soluble forms of adhesion molecules (Abe et al. 1998; Thies et al. 2001), while other studies report the opposite (Seljeflot et al. 1998; Johansen et al. 1999).

Results of fish oil experiments on plasma CRP concentrations also are inconsistent. Although a significant inverse correlation between serum CRP concentrations and content of DHA in granulocytes has been demonstrated (Madsen et al. 2001), a recent study by the same research group failed to reproduce this finding (Madsen et al. 2003). Similarly, the administration of $n-3$ PUFA to healthy individuals did not alter plasma CRP levels (Vega-Lopez et al. 2004).

Evidence since the 1950s has demonstrated that Mediterranean countries display rates of chronic diseases that are among the lowest in the world with corresponding life expectancies that are among the highest (Nestle, 1995). In a recent study conducted in the Greek population, the adoption of the Mediterranean diet by subjects with the metabolic syndrome was associated with a significant reduction of the risk of developing acute coronary events (Pitsavos et al. 2003).

Our objective was to examine the effect of dietary ALA on inflammatory markers and soluble cellular adhesion molecules (sCAM) related to atherosclerosis with regard to a dietary variable. For this purpose, volunteers were recruited who followed either a Mediterranean-Cretantype diet or a Westernised Greek diet.

\section{Subjects and methods}

\section{Subjects}

Subjects were recruited from the treadmill test unit in the Department of Cardiology of Laiko Hospital after screening by medical history, physical examination, electrocardiograph, and laboratory analysis. Fifty male volunteers aged 35 to 67 years, first diagnosed for dyslipidaemia, without evidence of CHD, were recruited. Entry criteria for recruitment included a total cholesterol concentration higher than $5.20 \mathrm{mmol} / \mathrm{l}$, and/or an HDL-cholesterol concentration lower than $1.03 \mathrm{mmol} / \mathrm{l}$. Subjects with evidence of infection or coexistent diabetes mellitus, hypertension, renal, liver or inflammatory disease were excluded. In addition, subjects taking lipid-lowering drugs, habitually consuming more than thirty units alcohol per week, smoking ten or more cigarettes per $\mathrm{d}$, or habitually vigorously exercising at the level of $>6 \mathrm{~h} /$ week were excluded. Of the fifty men enrolled, one withdrew before completion of the study because of gastrointestinal discomfort.
An additional nine subjects either withdrew or were excluded for non-compliance during the 12-week intervention. Thus, forty subjects completed the entire study.

\section{Study design}

A single intervention of parallel design was carried out. Dietary assessment was performed before the intervention to allocate volunteers according to their background diet into two groups. The first group was a group of subjects habitually following a diet characteristic of the so-called Mediterranean-Cretan diet as described in the Seven Countries Study (Kafatos et al. 2000) ( $n$ 21); the second group of subjects habitually followed a Westernised Greek diet ( $n$ 19).

All subjects were supplemented with $15 \mathrm{ml}$ flaxseed oil $/ \mathrm{d}$ for 12 weeks. Supplements contained approximately $8 \mathrm{~g}$ ALA ( $n-3)$ and were taken three times daily, one $5 \mathrm{ml}$ teaspoon/meal. The subjects were asked to maintain their dietary habits and usual lifestyle and were instructed to avoid the intake of anti-inflammatory drugs, vitamins or other dietary supplements throughout the intervention period. The subjects were supervised in respect of their dietary habits, alcohol consumption and physical activity habits by phone calls once per week and by visits to the hospital. The subjects were weighed monthly. At the time of the patient visits, they were provided with the oil supplements. Heights and weights were measured with the subjects in light clothing and shoes removed. Flaxseed-oil supplements were provided by Savant International (Savant Distribution Ltd, Leeds, UK). Flaxseed oil was extracted by cold pressing under $\mathrm{N}_{2}$. It was stored in brown bottles at $4^{\circ} \mathrm{C}$. No additional antioxidants were added. Fatty acid composition of the oil is given in Table 1. All subjects provided written informed consent, and the study protocol was approved by the ethical committee of Harokopio University.

\section{Diets}

Dietary assessments were based on a validated food-frequency questionnaire that included food items from the Mediterranean diet pyramid (Trichopoulou, 2000). Frequencies of milk and dairy products, bread, fruits, vegetables, legumes, olive oil, fish, poultry, red meat and meat products, and wine consumption were recorded and a monthly food consumption score calculated. Dietary compositions of the two groups are depicted in Table 2. Dietary compliance was assessed by a total of three $4 \mathrm{~d}$ dietary records (one every 4 weeks). The recorded days

Table 1. Fatty acid, total sterol and total tocopherol composition of the flaxseed oil (per $100 \mathrm{~g}$ )

\begin{tabular}{lr} 
Constituents & \\
\hline Palmitic acid (g) & $5 \cdot 9$ \\
Stearic acid (g) & 3.6 \\
Oleic acid (g) & $18 \cdot 2$ \\
Linoleic acid (g) & 13.9 \\
$\alpha$-Linolenic acid (g) & 54.2 \\
Total sterols (g) & 0.4 \\
Total tocopherols (mg) & 54.27
\end{tabular}


Table 2. Nutrient composition of the two diets

(Mean values and standard deviations)

\begin{tabular}{|c|c|c|c|c|c|}
\hline \multirow[t]{2}{*}{ Diet... } & \multicolumn{2}{|c|}{$\begin{array}{l}\text { Mediterranean-Cretan- } \\
\text { type diet }\end{array}$} & \multicolumn{2}{|c|}{$\begin{array}{l}\text { Westernised Greek } \\
\text { diet }\end{array}$} & \multirow[b]{2}{*}{$P$ value } \\
\hline & Mean & SD & Mean & SD & \\
\hline Energy $(J)$ & 9169.86 & 1118.46 & 9154.32 & $959 \cdot 28$ & 0.348 \\
\hline Proteins (\%) & $13 \cdot 2$ & 3.1 & $16 \cdot 0$ & 1.8 & 0.009 \\
\hline Carbohydrates (\%) & $47 \cdot 8$ & $3 \cdot 8$ & 44.4 & 4.4 & 0.007 \\
\hline Fats (\%) & $37 \cdot 7$ & 4.8 & $38 \cdot 2$ & 4.2 & 0.467 \\
\hline SFA (g) & $22 \cdot 3$ & 2.5 & $38 \cdot 6$ & 3.2 & 0.018 \\
\hline MUFA (g) & 49.5 & $5 \cdot 8$ & $32 \cdot 6$ & 4.9 & 0.034 \\
\hline PUFA (g) & $13 \cdot 7$ & $2 \cdot 0$ & $12 \cdot 1$ & 1.7 & 0.171 \\
\hline$\alpha$-Linolenic acid $(\mathrm{g})$ & 0.9 & 0.3 & $1 \cdot 1$ & 0.2 & 0.215 \\
\hline $\operatorname{EPA}(\mathrm{g})$ & 0.3 & 0.05 & 0.3 & 0.08 & 0.249 \\
\hline DHA (g) & 0.4 & 0.04 & 0.3 & 0.05 & 0.311 \\
\hline Cholesterol (mg) & 214.8 & 24.4 & $370 \cdot 1$ & 31.0 & 0.004 \\
\hline Alcohol \% & 1.3 & 0.3 & 1.4 & 0.4 & 0.741 \\
\hline Vitamin C (mg) & $122 \cdot 4$ & $13 \cdot 0$ & $117 \cdot 8$ & 18.4 & 0.002 \\
\hline Dietary fibre $(\mathrm{g})$ & $26 \cdot 7$ & $3 \cdot 3$ & $22 \cdot 4$ & $4 \cdot 1$ & 0.021 \\
\hline
\end{tabular}

SFA, saturated fatty acids; DHA, docosahexaenoic acid.

included three weekdays and one weekend day. The diet diaries were analysed using the Nutritionist V Diet Analysis software (version 2.1, First Data Bank Inc., San Bruno, CA, USA) as modified for the Greek population (Yannakoulia et al. 2003).

\section{Analytical procedures}

The volunteers attended the Department of Cardiology at Laiko Hospital on two occasions for blood collection; at the beginning and end of the experimental period. At each visit blood samples were collected at 08.00 hours after the subjects had fasted overnight $(12 \mathrm{~h})$. Blood was collected into a glass tube without preservative (vacutainer tube; Becton Dickinson Labware, Franklin Lakes, NJ, USA) for the determination of serum inflammatory indices. All samples were collected without occlusion. The vacutainer tubes were kept on ice until centrifuged at $3000 \mathrm{rpm}$ for $10 \mathrm{~min}$ at $4^{\circ} \mathrm{C}$ within $2 \mathrm{~h}$ of blood collection. Serum samples were stored at $-80^{\circ} \mathrm{C}$ for further analysis. CRP and serum amyloid A (SAA) were assayed by particle-enhanced immunonephelometry (N Latex; Date-Behring Marburg GmbH, Marburg, Germany) with a range from 0.175 to $1100 \mathrm{mg} / \mathrm{l}$ and 0.75 to $1000 \mathrm{mg} / \mathrm{l}$, respectively. IL-6 and macrophage colony-stimulating factor (MCSF) were measured by high-sensitivity ELISA (R \& D Systems Europe Ltd, Abingdon, Oxfordshire, UK). The intra-assay and inter-assay $\mathrm{CV}$ were $<5 \%$ for CRP, SAA and MCSF and $<10 \%$ for IL-6. Soluble vascular cell adhesion molecule-1, soluble intercellular adhesion molecule-1 and soluble E-selectin were assayed by quantitative sandwich ELISA ( $\mathrm{R} \& \mathrm{D}$ Systems Europe Ltd). The intra-assay and inter-assay $\mathrm{CV}$ for sCAM was $<10 \%$. All samples were assayed twice by a single operator blinded to sample timing and diet category. To minimise variability, samples before and after the ALA supplementation for each subject were run in one assay. All measurements were performed at the biochemistry laboratory of the General Hospital of Nikea.

\section{Statistical analysis}

Clinical and dietary traits are expressed as mean values and standard deviations, unless otherwise stated. Data on inflammatory markers and adhesion molecules were not normally distributed and therefore were expressed as the median and the 25th and 75th percentiles. Differences in the baseline concentrations of clinical and dietary traits between diet groups were assessed using Student's independent samples $t$ tests (after log transformation), with the exception of smoking status where the $\chi^{2}$ test was used. Since data on inflammatory markers and sCAM concentrations were not normally distributed even after the logarithmic transformation of the values, nonparametric analyses were performed to determine differences at baseline (Mann-Whitney $U$ test), and before and after ALA supplementation (Wilcoxon signed ranks test). The Mann-Whitney $U$ test also was used to compare percentage differences of inflammatory markers and SCAM concentrations before and after the ALA supplementation period between the two diet groups. Percentage difference was calculated as the median of the percentage differences of individual values. Statistical significance was set at $P<0.05$. Data were analysed using SPSS statistical software (SPSS for Windows, version 10.0.5; SPSS Inc., Chicago, IL, USA).

\section{Results}

\section{Baseline characteristics}

The subjects enrolled in the two dietary groups did not differ in regard to age, BMI, blood pressure and leucocyte, lymphocyte, or monocyte-granulocyte count. The number of light smokers (less than ten cigarettes per d) was similar across the two groups (Table 3).

Body weight and leucocyte, lymphocyte, and monocyte-granulocyte counts did not change significantly during the course of the study. A review of diet diaries indicated that the subjects' background diet remained unchanged throughout the study. 
Table 3. Baseline clinical data of the two different background diet groups (Mean values and standard deviations)

\begin{tabular}{|c|c|c|c|c|c|}
\hline \multirow{2}{*}{$\begin{array}{l}\text { Diet... } \\
\text { Variable }\end{array}$} & \multicolumn{2}{|c|}{$\begin{array}{c}\text { Mediterranean-Cretan- } \\
\text { type diet }(n 21)\end{array}$} & \multicolumn{2}{|c|}{$\begin{array}{l}\text { Westernised Greek diet } \\
\qquad(n 19)\end{array}$} & \multirow[b]{2}{*}{$P$ value } \\
\hline & Mean & SD & Mean & SD & \\
\hline Age (years) & $50 \cdot 2$ & $6 \cdot 3$ & $48 \cdot 7$ & $8 \cdot 3$ & NS \\
\hline $\mathrm{BMI}\left(\mathrm{kg} / \mathrm{m}^{2}\right)$ & $28 \cdot 6$ & $3 \cdot 6$ & $27 \cdot 8$ & $3 \cdot 6$ & NS \\
\hline Leucocytes $\left(\times 10^{3}\right)$ & 6.4 & 1.6 & $7 \cdot 3$ & 1.9 & NS \\
\hline Neutrophils $\left(\times 10^{3}\right)$ & $3 \cdot 8$ & $1 \cdot 1$ & $4 \cdot 1$ & $1 \cdot 3$ & \\
\hline Lymphocytes $\left(\times 10^{3}\right)$ & $2 \cdot 2$ & 0.9 & $2 \cdot 3$ & 0.7 & NS \\
\hline Monocytes $\left(\times 10^{3}\right)$ & 0.32 & 0.12 & 0.37 & 0.14 & NS \\
\hline \multicolumn{6}{|l|}{ Blood pressure $(\mathrm{mmHg})$} \\
\hline Systolic & $126 \cdot 6$ & 16 & $125 \cdot 6$ & $16 \cdot 7$ & NS \\
\hline Diastolic & 80.8 & 11 & $80 \cdot 2$ & 11 & NS \\
\hline Light smokers: yes $(n)$ & \multicolumn{2}{|c|}{4} & \multicolumn{2}{|c|}{4} & NS \\
\hline no $(n)$ & \multicolumn{2}{|c|}{17} & \multicolumn{2}{|c|}{15} & \\
\hline
\end{tabular}

\section{Blood inflammatory markers}

Median values of SAA, CRP, MCSF and IL-6 of the two dietary groups before and after the ALA supplementation are presented in Table 4 . The only inflammatory marker to present a statistically significant reduction in both groups after ALA supplementation was MCSF, while CRP, SAA and IL-6 were decreased significantly, but only in the Westernised Greek diet group. The difference of response of the inflammatory markers to the ALA supplementation in the two background diets was confirmed by comparison of percentage differences within each of the two diet groups (Fig. 1). Percentage changes of SAA and CRP in the Westernised Greek diet group were significantly different from changes in the group following the Mediterranean-Cretan-type diet $(P=0.005$ and $P=0.038$, respectively). No significant correlations were found between dietary cholesterol, saturated fatty acids, MUFA and PUFA, and the investigated inflammatory markers in the two groups. Furthermore, correlations between dietary vitamin $C$ intake and inflammatory markers were not statistically significant.

\section{Soluble cellular adhesion molecules}

Levels of soluble vascular cell adhesion molecule-1 decreased significantly with ALA supplementation in both patient groups $(P<0.001$ in the MediterraneanCretan-type diet and $P=0.001$ in the Westernised Greek diet). The levels of soluble intercellular adhesion molecule and soluble E-selectin also remained unaltered in both groups (Table 5).

\section{Discussion}

Our data reveal that an increased dietary intake of ALA for 3 months was sufficient to reduce inflammatory markers and soluble vascular cell adhesion molecule-1 concentrations in dyslipidaemic subjects. This effect was more evident for the group following the Westernised Greek diet compared with the group following the Mediterranean-Cretan-type diet.

Nutrient intakes were different in the two diet groups. The Westernised Greek diet group showed higher intakes of protein, while carbohydrate intakes were lower

Table 4. Serum concentrations of inflammatory markers in dyslipidaemic volunteers following two different background diets before and after $\alpha$-linolenic acid supplementation*

(Median values and 25th and 75th percentiles)

\begin{tabular}{|c|c|c|c|c|c|c|}
\hline \multirow[b]{2}{*}{ Variables } & \multicolumn{2}{|r|}{ Before† } & \multicolumn{2}{|r|}{ After } & \multirow[b]{2}{*}{ Percentage difference $\ddagger$} & \multirow[b]{2}{*}{$P$ value } \\
\hline & Median & 25th-75th percentile & Median & 25th-75th percentile & & \\
\hline \multicolumn{7}{|c|}{ Mediterranean-Cretan-type diet group ( $n 21)$} \\
\hline $\mathrm{SAA}(\mathrm{mg} / \mathrm{l})$ & 2.51 & $2 \cdot 20-4.5$ & 2.40 & $1 \cdot 70-3 \cdot 00$ & $-3 \cdot 6$ & $0 \cdot 16$ \\
\hline $\mathrm{CRP}(\mathrm{mg} / \mathrm{l})$ & 0.96 & $0.54-1.82$ & 0.99 & $0.56-2 \cdot 10$ & $2 \cdot 0$ & 0.51 \\
\hline $\operatorname{MCSF}(\mathrm{pg} / \mathrm{ml})$ & 283 & $257-309$ & 258 & $226-292$ & $-15 \cdot 0$ & 0.006 \\
\hline IL-6 (pg/ml) & 2.0 & $1 \cdot 12-3 \cdot 15$ & 1.66 & $0.99-2.13$ & -4.5 & 0.08 \\
\hline \multicolumn{7}{|c|}{ Westernised Greek diet group ( $n 19)$} \\
\hline SAA (mg/l) & 3.65 & $2 \cdot 5-5 \cdot 8$ & $2 \cdot 38$ & $1.39-3.40$ & $-36 \cdot 4$ & 0.0002 \\
\hline $\mathrm{CRP}(\mathrm{mg} / \mathrm{l})$ & $1 \cdot 8$ & $1 \cdot 19-4.4$ & $1 \cdot 10$ & $0.59-1.60$ & $-36 \cdot 1$ & 0.002 \\
\hline $\operatorname{MCSF}(\mathrm{pg} / \mathrm{ml})$ & 279 & $237-328$ & $232 \cdot 0$ & $195 \cdot 0-284.0$ & $-21 \cdot 9$ & 0.005 \\
\hline IL-6 (pg/ml) & $2 \cdot 28$ & $1 \cdot 34-4 \cdot 80$ & $1 \cdot 70$ & $1 \cdot 26-2 \cdot 40$ & -7.9 & 0.03 \\
\hline
\end{tabular}

SAA, serum amyloid A; CRP, C-reactive protein; MCSF, macrophage colony-stimulating factor.

${ }^{*}$ For details of subjects and diets, see Tables 1-3 and pp. 650-652.

†The median values of the inflammatory markers for the Mediterranean-Cretan-type diet group were not significantly different from the corresponding values for the Westernised Greek diet group at baseline.

$\ddagger$ Percentage difference was calculated as the median of the percentage differences of individual values. 


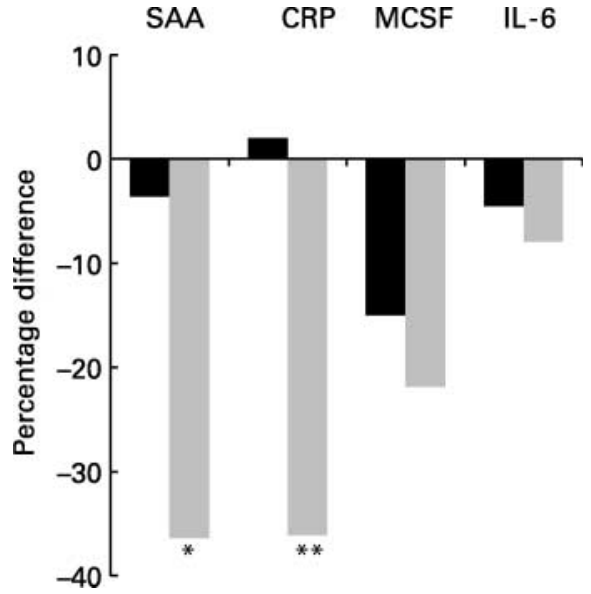

Fig. 1. Percentage differences of concentrations of inflammatory markers after the $\alpha$-linolenic acid supplementation of subjects with the two different background diets, the Mediterranean-Cretan-type diet $(\square)$ and the Westernised Greek diet $(\square)$. SAA, serum amyloid A; CRP, C-reactive protein; MCSF, macrophage colony-stimulating factor. Percentage difference was calculated as the median of the percentage differences of individual values. The comparison of percentage differences was made by the Mann-Whitney $U$ test. There were significant differences between the two diet groups: * $P<0.05$, ** $P<0.01$.

compared with the Mediterranean-Cretan-type diet group. Intakes of saturated fatty acids and cholesterol were significantly higher in the Westernised Greek diet group than the Mediterranean-Cretan-type diet group. Approximately $16 \%$ of energy intakes in the Westernised Greek diet group came from saturated fatty acids, a pattern that would be considered high when compared with the American Heart Association recommendations (Expert Panel on Detection, Evaluation, and Treatment of High Blood Cholesterol in Adults, 2001). On the other hand, the Mediterranean-Cretan-type diet group showed a higher intake of MUFA, vitamin C and dietary fibre. These intakes are in accord with the basic definition of the MediterraneanCretan diet (Kafatos et al. 2000) and the 'Westernised' diet profile (Lewis et al. 1981), respectively.

Atherosclerosis is a chronic inflammatory disorder characterised by a dynamic interaction of inflammatory cells, cytokines and chemokines (Ross, 1999). Leucocyte adhesion to endothelial cells and subsequent transendothelial migration, an initial event in the atherosclerotic process, is largely mediated by cell adhesion molecules (Price \& Loscalzo, 1999). The sCAM originate from the shedding or proteolytic cleavage of membrane-bound molecules and may serve as markers of endothelial cell activation (Gearing \& Newman, 1993). On the other hand, there is growing evidence that inflammatory markers such as CRP may also play a direct pathogenic role in the atherosclerotic process (Pasceri et al. 2000). Other inflammatory markers such as SAA, MCSF and IL-6 are present in atherosclerotic lesions and research has suggested that these markers play a role in the development of atherosclerotic plaques (Clinton et al. 1992; Meek et al. 1994; DeGraba, 1997). Such results indicate the importance of interventions aimed at the reduction of inflammatory markers, which may be translated in clinical benefit regarding the prevention of CHD.

As we have previously reported (Rallidis et al. 2003), dietary ALA supplementation reduces the concentrations of inflammatory markers. The mechanisms responsible for the suppression of the concentrations of inflammatory markers by ALA, however, remain unknown, although suppression of eicosanoid production may be involved (James et al. 2000). We have proposed elsewhere that the reduction of prostaglandin $\mathrm{E}_{2}$ and leucotriene $\mathrm{B}_{4}$ production and the subsequent reduction of pro-inflammatory cytokines IL- 1 and TNF- $\alpha$ decreases IL- 6 release which in turn reduces the hepatic production of CRP and SAA (Rallidis et al. 2003). IL-1 and TNF- $\alpha$ are known to induce a large increase in MCSF secretion from both vascular endothelial and smooth muscle cells in cultures (Clinton et al. 1992), and thus control MCSF expression. Moreover, cellular adhesion molecules are expressed on the endothelial membrane in response to several inflammatory stimuli, such as CRP and pro-inflammatory cytokines (Price \& Loscalzo, 1999).

The present study was designed to investigate associations between the anti-inflammatory effect of ALA and background dietary patterns. We report here a greater responsiveness of the inflammatory markers in the

Table 5. Soluble cellular adhesion molecule concentrations in dyslipidaemic volunteers following two different background diets before and after $\alpha$-linolenic acid supplementation*

(Median values and 25th and 75th percentiles)

\begin{tabular}{|c|c|c|c|c|c|c|}
\hline \multirow[b]{2}{*}{ Variables } & \multicolumn{2}{|r|}{ Before } & \multicolumn{2}{|r|}{ After } & \multirow[b]{2}{*}{ Percentage differenceł } & \multirow[b]{2}{*}{$P$ value } \\
\hline & Median & 25th-75th percentile & Median & 25th-75th percentile & & \\
\hline \multicolumn{7}{|c|}{ Mediterranean-Cretan-type diet group $(n 21)$} \\
\hline sVCAM-1 (ng/ml) & 610 & $534-787$ & 543 & $487-601$ & $-10 \cdot 1$ & $<0.001$ \\
\hline sICAM-1 (ng/ml) & 201 & $173-232$ & 204 & $173-254$ & 1.7 & 0.19 \\
\hline sE-selectin (ng/ml) & $44 \cdot 2$ & $35 \cdot 0-55 \cdot 1$ & $44 \cdot 0$ & $37 \cdot 5-55 \cdot 1$ & -3.9 & 0.99 \\
\hline \multicolumn{7}{|c|}{ Westernised Greek diet group $(n 19)$} \\
\hline sVCAM-1 (ng/ml) & 592 & $506-625$ & 495 & $430-570$ & $-18 \cdot 3$ & 0.001 \\
\hline sICAM-1 (ng/ml) & 219 & $196-264$ & 222 & $192-279$ & 0.1 & 0.91 \\
\hline $\mathrm{sE}-$ selectin $(\mathrm{ng} / \mathrm{ml})$ & $47 \cdot 8$ & $31 \cdot 6-65.9$ & $47 \cdot 8$ & $31 \cdot 6-67 \cdot 1$ & -2.9 & 0.31 \\
\hline
\end{tabular}

sVCAM-1, soluble vascular cell adhesion molecule-1; sICAM-1, soluble intercellular adhesion molecule-1; SE-selectin, soluble E-selectin.

${ }^{*}$ For details of subjects and diets, see Tables 1-3 and pp. 650-652.

†The median values of the soluble cellular adhesion molecules for the Mediterranean-Cretan-type diet group were not significantly different from the correspond-

ing values for the Westernised Greek diet group at baseline.

$\ddagger$ Percentage difference was calculated as the median of the percentage differences of individual values. 
Westernised Greek diet group. Still, we found no correlations between the dietary intake of specific nutrients and concentration of inflammatory markers. Animal studies, however, have demonstrated suppressive effects of individual nutrients, such as oleic acid on in vivo immune responses (Yaqoob, 2002), while a high-MUFA diet resulted in a reduction in the expression of adhesion molecules by human peripheral blood mononuclear cells (Yaqoob et al. 1998). A limited number of studies have suggested an anti-inflammatory effect of vitamin C. An association between vitamin $\mathrm{C}$ deficiency and immune dysfunction has been reported (Schoenherr \& Jewell, 1997). Serum CRP concentrations have been correlated negatively with serum vitamin $\mathrm{C}$ concentration in peripheral arterial disease (Langlois et al. 2001), and critically ill patients (Schorah et al. 1996). Although intakes of MUFA and vitamin $\mathrm{C}$ were different in the two diet groups we investigated, our data do not reveal a direct correlation between the dietary intake of these nutrients and the anti-inflammatory effect of ALA.

One limitation of the present study is the lack of a control group. A second limitation is that plasma phospholipid fatty acid composition data were not collected; therefore, associations between fatty acids and inflammatory markers could not be drawn. Still, our data on dietary fatty acid composition, based upon participants' dietary diaries, revealed no association. Furthermore, no associations were observed between vitamin $\mathrm{C}$ and inflammatory markers, although these nutrients were consumed in different quantities by the two dietary groups. Although our data indicated that some inflammatory markers were decreased more when ALA was supplemented in Westernised diets compared with a Mediterranean diet, our data could not confirm that the Mediterranean diet possessed an intrinsic anti-inflammatory effect.

In conclusion, we speculate that ALA supplementation would be more effective in the reduction of some inflammatory markers if patients were consuming a Westernised diet, rather than a Greek-Mediterranean type of diet. The mechanisms for these effects remain to be elucidated.

\section{Acknowledgements}

The authors thank Dr E. Karpodini, Dr E. Theriou, and the staff of the Department of Cardiology, Laiko Hospital, for assistance with the management of the subjects. We also wish to thank Dr N. Yiannakouris (Harokopio University) for his review of the manuscript. This project was supported by the Greek Ministry of Development, General Secretariat for Research and Technology (grant 97EL-55) and in part by Becel Institute/Unilever Bestfoods Greece.

\section{References}

Abe Y, El-Masri B, Kimball KT, Pownall H, Reilly CF, Osmundsen K, Smith CW \& Ballantyne CM (1998) Soluble cell adhesion molecules in hypertriglyceridemia and potential significance on monocyte adhesion. Arterioscler Thromb Vasc Biol 18, 723-731.
Ascherio A, Rimm EB, Stampfer MJ, Giovannucci EL \& Willett WC (1995) Dietary intake of marine n-3 fatty acids, fish intake, and the risk of coronary disease among men. $N$ Engl $J$ Med 332, 977-982.

Blok WL, Deslypere JP, Demacker PN, van der Ven-Jongekrijg J, Hectors MP, van der Meer JW \& Katan MB (1997) Pro- and anti-inflammatory cytokines in healthy volunteers fed various doses of fish oil for 1 year. Eur J Clin Invest 27, 1003-1008.

Calder PC (2001) Omega 3 polyunsaturated fatty acids, inflammation and immunity. World Rev Nutr Diet 88, 109-116.

Caughey GE, Mantzioris E, Gibson RA, Cleland LG \& James MJ (1996) The effect on human tumor necrosis factor alpha and interleukin 1 beta production of diets enriched in n-3 fatty acids from vegetable oil or fish oil. Am J Clin Nutr 63, $116-122$.

Clinton SK, Underwood R, Hayes L, Sherman ML, Kufe DW \& Libby P (1992) Macrophage colony-stimulating factor gene expression in vascular cells and in experimental and human atherosclerosis. Am J Pathol 140, 301-316.

Collie-Duguid ESR \& Wahle KWJ (1996) Inhibitory effect of fish oil n-3 polyunsaturated fatty acids on the expression of endothelial cell adhesion molecules. Biochem Biophys Res Commun 220, 969-974.

De Caterina R, Cybulsky MI, Clinton SK, Gimbrone MA Jr \& Libby P (1994) The omega-3 fatty acid docosahexaenoate reduces cytokine-induced expression of pro-atherogenic and pro-inflammatory proteins in human endothelial cells. Arterioscler Thromb 14, 1829-1836.

DeGraba TJ (1997) Expression of inflammatory mediators and adhesion molecules in human atherosclerotic plaque. Neurology 49, 15-19.

Endres S, Ghorbani R, Kelley VE, et al. (1989) The effect of dietary supplementation with $n-3$ polyunsaturated fatty acids on the synthesis of interleukin-1 and tumor necrosis factor by mononuclear cells. $N$ Engl J Med 320, 265-271.

Expert Panel on Detection, Evaluation, and Treatment of High Blood Cholesterol in Adults (2001) Executive Summary of The Third Report of the National Cholesterol Education Program (NCEP) Expert Panel on Detection, Evaluation, and Treatment of High Blood Cholesterol in Adults (Adult Treatment Panel III). JAMA 285, 2486-2497.

Gearing AJ \& Newman W (1993) Circulating adhesion molecules in disease. Immunol Today 14, 506-512.

James MJ, Gibson RA \& Cleland LG (2000) Dietary polyunsaturated fatty acids and inflammatory mediator production. Am J Clin Nutr 71, 343-348.

Johansen O, Seljeflot I, Hostmark AT \& Arnesen H (1999) The effect of supplementation with omega-3 fatty acids on soluble markers of endothelial function in patients with coronary heart disease. Arterioscler Thromb Vasc Biol 19, 1681-1686.

Kafatos A, Verhagen H, Moschandreas J, Apostolaki I \& van Westerop JJ (2000) Mediterranean diet of Crete: foods and nutrient content. J Am Diet Ass 100, 1487-1493.

Kew S, Banerjee T, Minihane AM, Finnegan YE, Muggli R, Albers R, Williams CM \& Calder PC (2003) Lack of effect of foods enriched with plant- or marine-derived n-3 fatty acids on human immune function. Am J Clin Nutr 77, 1287-1295.

Khalfoun B, Thibault G, Bardos P \& Lebranchu Y (1996) Docosahexaenoic and eicosapentaenoic acids inhibit in vitro human lymphocyte-endothelial cell adhesion. Transplantation 62, 1649-1657.

Langlois M, Duprez D, Delanghe J, De Buyzere M \& Clement DL (2001) Serum vitamin C concentration is low in peripheral arterial disease and is associated with inflammation and severity of atherosclerosis. Circulation 103, 1863-1868. 
Lewis B, Hammett F, Katan M, Kay RM, Merkx I, Nobels A, Miller NE \& Swan AV (1981) Towards an improved lipid-lowering diet: additive effects of changes in nutrient intake. Lancet ii, 1310-1313.

Madsen T, Christensen JH, Blom M \& Schmidt EB (2003) The effect of dietary n-3 fatty acids on serum concentrations of C-reactive protein: a dose-response study. Br J Nutr 89, 517-522.

Madsen T, Skou HA, Hansen VE, Fog L, Christensen JH, Toft E \& Schmidt EB (2001) C-reactive protein, dietary n-3 fatty acids, and the extent of coronary artery disease. Am J Cardiol 88, 1139-1142.

Meek RL, Urieli-Shoval S \& Benditt EP (1994) Expression of apolipoprotein serum amyloid A mRNA in human atherosclerotic lesions and cultured vascular cells: implications for serum amyloid A function. Proc Natl Acad Sci USA 91, 3186-3190.

Meydani SN, Endres S, Woods MM, Goldin BR, Soo C, MorrillLabrode A, Dinarello CA \& Gorbach SL (1991) Oral (n-3) fatty acid supplementation suppresses cytokine production and lymphocyte proliferation: comparison between young and older women. J Nutr 121, 547-555.

Nestle M (1995) Mediterranean diets: historical and research overview. Am J Clin Nutr 61, 1313-1320.

Pasceri V, Willerson JT \& Yeh ETH (2000) Direct proinflammatory effect of C-reactive protein on human endothelial cells. Circulation 102, 2165-2168.

Pitsavos C, Panagiotakos DB, Chrysohoou C, Papaioannou I, Papadimitriou L, Tousoulis D, Stefanadis C \& Toutouzas P (2003) The adoption of Mediterranean diet attenuates the development of acute coronary syndromes in people with the metabolic syndrome. Nutr $J \mathbf{2}, 1$.

Price DT \& Loscalzo J (1999) Cellular adhesion molecules and atherogenesis. Am J Med 107, 85-97.

Rallidis LS, Paschos G, Liakos GK, Vellissaridou AH, Anastasiadis G \& Zampelas A (2003) Dietary $\alpha$-linolenic acid decreases C-reactive protein, serum amyloid A and interleukin-6 in dyslipidaemic patients. Atherosclerosis 167, 237-242.

Ross R (1999) Atherosclerosis: an inflammatory disease. N Engl J Med 340, 115-126.

Schmidt EB, Varming K, Moller JM, Bulow Pedersen I, Madsen P \& Dyerberg J (1996) No effect of a very low dose of n-3 fatty acids on monocyte function in healthy humans. Scand J Clin Lab Invest 56, 87-92.
Schoenherr WD \& Jewell DE (1997) Nutritional modification of inflammatory diseases. Semin Vet Med Surg 12, 212-222.

Schorah CJ, Downing C, Piripitsi A, Gallivan L, Al-Hazaa AH, Sanderson MJ \& Bodenham A (1996) Total vitamin C, ascorbic acid, and dehydroascorbic acid concentrations in critically ill patients. Am J Clin Nutr 63, 760-765.

Seljeflot I, Arnesen H, Brude IR, Nenseter MS, Drevon CA \& Hjermann I (1998) Effects of omega-3 fatty acids and/or antioxidants on endothelial cell markers. Eur J Clin Invest $\mathbf{2 8}$ $629-635$.

Thies F, Miles EA, Nebe-von-Caron G, Powell JR, Hurst TL, Newsholme EA \& Calder PC (2001) Influence of dietary supplementation with long-chain $n-3$ or $n-6$ polyunsaturated fatty acids on blood inflammatory cell populations and functions and on plasma soluble adhesion molecules in healthy adults. Lipids 36, 1183-1193.

Trichopoulou A (2000) From research to education: the Greek experience. Nutrition 16, 528-531.

Vega-Lopez S, Kaul N, Devaraj S, Cai RY, German B \& Jialal I (2004) Supplementation with omega3 polyunsaturated fatty acids and all-rac alpha-tocopherol alone and in combination failed to exert an anti-inflammatory effect in human volunteers. Metabolism 53, 236-240.

Weber C, Erl W, Pietsch A, Danesch U \& Weber PC (1995) Docosahexaenoic acid selectively attenuates induction of vascular cell adhesion molecule-1 and subsequent monocytic cell adhesion to human endothelial cells stimulated by tumor necrosis factor- $\alpha$. Arterioscler Thromb Vasc Biol 15, $622-628$.

Yannakoulia M, Yiannakouris N, Bluher S, Matalas AL, KlimisZacas D \& Mantzoros CS (2003) Body fat mass and macronutrient intake in relation to circulating soluble leptin receptor, free leptin index, adiponectin, and resistin concentrations in healthy humans. J Clin Endocrinol Metab 88, 1730-1736.

Yaqoob P (2002) Monounsaturated fatty acids and immune function. Eur J Clin Nutr 56, 9-13.

Yaqoob P, Knapper JA, Webb DH, Williams CM, Newsholme EA \& Calder PC (1998) Effect of olive oil on immune function in middle-aged men. Am J Clin Nutr 67, 129-135.

Yaqoob P, Pala HS, Cortina-Borja M, Newsholme EA \& Calder PC (2000) Encapsulated fish oil enriched in alpha-tocopherol alters plasma phospholipid and mononuclear cell fatty acid compositions but not mononuclear cell functions. Eur J Clin Invest 30, 260-274. 